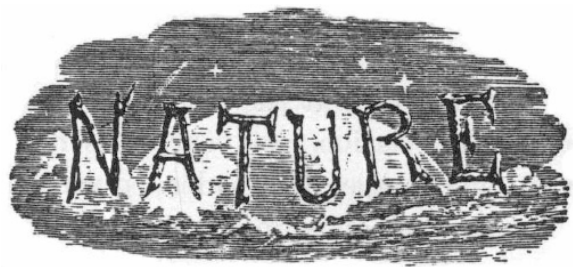

SATURDAY, MAY 4, I935

No. 3418

Vol. 135

\section{Tribute of Science to the Royal Jubilee}

$A^{M O N G}$ the addresses received by H.M. the A King after his accession to the Throne on May 6, 1910, was one from the Royal Society, in which reference was made to the interest which His Majesty, when Prince of Wales, had continually shown in the progress of discovery and invention. In consenting to succeed his father, King Edward, as Patron of the Society, King George expressed appreciation of these elements of national greatness, and assured the deputation of his "sympathy and support in your beneficent efforts for the promotion of natural knowledge". The collection of articles which appears in this special issue of NATuRE, nearly all of which are by fellows of the Society, indicates some of the directions in which these efforts have been remarkably successful by adding new realms to the empire of science and conducting profitable explorations in them.

Science, like the universe, has no natural partitions either in space or time; so that any record of its achievements cannot be limited to a particular period or country. It happens, however, that the twenty-five years now being celebrated as the jubilee of the King's reign have seen a greater number of creative ideas in science than any corresponding period in the history of the world, and also that the contributions of British investigators to the rich harvest of scientifio knowledge which has been gathered in are both distinctive and of supreme importance. The articles outline some of the fertile fields of research opened up during the past quarter of a century; and it is impossible to read them without realising that we are living in a golden age of scientific discovery. The talents with which scientific workers have been entrusted have been used to full purpose ; and the results obtained are worthy of both royal and national pride.
In the main part the results represent scientific researches undertaken purely with the view of revealing natural phenomena and discovering new relationships or interpretations of them. This urge to penetrate into the unknown and reveal its mysteries cannot be repressed any more than can creative expression in art or literature. When, however, the spirit of an age is sympathetic towards any such intellectual activities, their advancement is increasingly ensured. On this account, acknowledgment must be made of the part played by the Department of Scientific and Industrial Research in the increase and use of natural knowledge. The Department was formed during the War as the result of a memorial from the Royal Society and other scientific and technical societies, exactly twenty years ago, urging the Government to afford assistance "for scientific research for industrial purposes". Two years later, Parliament placed a sum of one million pounds sterling at the disposal of the Committee of Council for the promotion of industrial research; and since then the Depart. ment instituted by the Committee has devoted a large part of the funds it derives from the State to fundamental scientific research in universities and other institutions, as well as in the promotion of research directly applied to industry. Two other national research organisations which have come into being during the past twenty-five years are the Medical Research Council and the Agricultural Research Council. The former arose from the Medical Research Committee, which was appointed for the purpose of dealing with the money available for research under the National Health Insurance Act of 1911 ; and provision for organised research in agriculture may be said to have grown up from the Development Act of 1909.

In addition to these and other endowments of research provided by the State since King George's accession to the Throne, there have been several munificent benefactions from private sources to establish research institutions or explore specific fields of investigation. On account of these extended facilities, the number of students and others engaged in scientific or industrial research has been multiplied many times during the past quarter of a century; and the output of original papers has increased to such an extent as to be unwieldy, and even oppressive, to scientific workers who desire to keep in touch with advances in their subjects. Our own correspondence columns represent this stream of tendency on a small scale, 
yet they are but a rivulet of the broad and swift river which is bearing rich cargoes of new knowledge to peoples along its banks and to ports in the seas beyond.

To attempt to survey adequately the scope and substance of scientific publications of even a single week would be to undertake a hopeless task. It is easy to understand, therefore, how incomplete any record must be which has to take a retrospective view of scientific progress in a period of twenty-five years. Obviously the only practicable plan is to select for description subjects which have opened new epochs of scientific history during the reign of the King, and not to endeavour to summarise developments in various branches of the physical or biological sciences. Beginning, for example, with the stellar universe, the knowledge gained during this period has led to entirely new conceptions as to its dimensions and structure, and their relation to the principle of relativity. Coming down to the earth, the views now generally accepted as to its age and constitution differ substantially from those formerly held, and are based upon firmer foundations. From the planet earth it is a natural transition to the planetary microcosm of the atom. Closely related are such subjects as isotopes, induced radioactivity, crystal structure, cosmic rays, the attainment of low temperatures, the constitution of the upper air, and weather forecasting. As to man himself, new light has been thrown on his ancestry and the factors favourable to his healthy development or injurious to it, as well as on the problems of heredity involved in his future. Chemistry is largely concerned with these and other biological problems, and has been able to give new aspects to them. In applied science the discovery of special steels has been largely responsible for progress in many directions, and without them there could not have been the remarkable developments in X-ray apparatus, radio communication through the use of thermionic valves, aeronauties or turbine machinery. These are the considerations which have decided the general order of the thirty articles now published.

The advances of knowledge have been accompanied by noteworthy changes of attitude of science towards philosophic and social problems. The im. plications of the theories of relativity and quanta, particularly in relation to notions of space and time, brought the physicist and mathematician into the realm of philosophy, while the philosopher has been giving attention to fruitful work in such specific problems as the nature of sense-data and their relation to physical entities, the character of space and time in their relation to one another, the basis of scientific induction, the interpretation of life and other intellectual concepts. Modern physical interpretations of the nature of the universe have thus led to the discussion and development of associated metaphysical problems, and the two fields of thought are now regarded as complementary to one another.

The view that the sole function of science is the discovery and study of fact, without regard to the philosophic or ethical implications of the knowledge gained, has undergone great modification in many minds. It is realised that science cannot be divorced from ethics or rightly absolve itself from the human responsibilities in the application of its discoveries to destructive purposes in war or economic disturbances in times of peace. Men of science can no longer stand aside from the social and political questions involved in the structure which has been built up from the materials provided by them, and which their discoveries may be used to destroy. It is their duty to assist in the establishment of a rational and harmonious social order out of the welter of human conflict into which the world has been thrown through the release of uncontrolled sources of industrial production and of lethal weapons.

It would scarcely be appropriate to deal with these aspects of scientific progress in the present collection of articles, though they are likely to become of increasing importance in national polity and international adjustments. We believe, however, that the wide range and high authority of the contributions now brought together in celebration of the silver jubilee of the King's reign are worthy of the occasion. It would be easy, of course, to point to other subjects which might have been included appropriately in such a retrospective survey; but, on the other hand, it would have been most regrettable to omit a single one of the present contributions, and these by themselves would make a volume of reasonable size if published in that form instead of the pages of Nature. The articles are offered as a tribute of loyalty from scientific workers to the King and Queen; and it is hoped that they will be regarded as a stimulating conspectus of advances in natural knowledge during a memorable twenty-five years. 